\title{
Visual field loss following vitrectomy for stage 2 and 3 macular holes
}

\author{
E Ezra, G B Arden, P Riordan-Eva, GW Aylward, Z J Gregor
}

\begin{abstract}
Aim-To describe the phenomenon of peripheral field loss following routine pars plana vitrectomy for stage 2 and 3 full thickness macular hole and to investigate the underlying mechanism.

Methods-Five patients, who reported peripheral field defects after apparently uncomplicated vitrectomy, posterior cortical vitreous peeling, and perfluoropropane $\left(C_{3} F_{8}\right)$ gas tamponade, were studied retrospectively with slit-lamp biomicroscopy, automated and kinetic perimetry, fundal fluorescein angiography, focal electroretinography (ERG), and colour contrast sensitivity (CCS) testing.

Results-All five patients, who were between 50 and 73 years of age, reported an inferotemporal field defect following resolution of the intraocular gas bubble. In all eyes, the scotomata encroached to within $20^{\circ}$ to $30^{\circ}$ of fixation and to within $5^{\circ}$ to $15^{\circ}$ of the blind spot. In one eye, a partial altitudinal component was evident. All scotomata subsequently remained stable and three eyes developed subtle segmental nasal disc pallor and nerve fibre loss corresponding to the field defect. CCS testing revealed absent colour contrast in the scotomatous area, in the presence of a preserved focal quadrantic flash ERG, compared with normal CCS protan thresholds and focal ERGs in unaffected quadrants, indicating preserved outer retinal function in the area of the scotoma. Conclusions-These observations support the hypothesis that field defects occur as a result of retinal nerve fibre layer damage. It is proposed, on the basis of intraoperative observations and other evidence, that the most likely site of nerve fibre damage is at the nasal portion of the optic nerve rim or peripapillary retina, probably due to traction during cortical vitreous peeling.
\end{abstract}

(Br f Ophthalmol 1996;80:519-525)

Department,

Moorfields Eye

Hospital, London

G B Arden

Neuro-ophthalmology Unit, Moorfields Eye

Hospital, London

P Riordan-Eva

Correspondence to:

Mr Z J Gregor, Vitreo-retinal

Unit, Moorfields Eye

Hospital, London EC1V

2PD.

Accepted for publication 7 March 1996

The hypothesis that tangential vitreomacular traction leads to the formation of idiopathic full thickness macular holes (FTMH), ${ }^{12}$ has led to the use of pars plana vitrectomy, posterior cortical vitreous peeling, and long acting intraocular gas tamponade for its treatment. Several studies have shown this to be effective in closing FTMHs and producing significant improvement in visual acuity. ${ }^{3-9}$ Peeling of adherent posterior cortical vitreous is considered an integral part of the procedure for stage 2 and 3 FTMHs. ${ }^{2-9}$ It is effected by engaging cortical vitreous with active aspiration using the vitreous cutter or a soft tipped cannula, ${ }^{3}$ and stripping anteriorly. Alternatively, passive aspiration may be used. The manoeuvre may be associated with a significant risk of intraoperative retinal breaks due to vitreoretinal traction..$^{49}$ We describe five patients who developed peripheral field loss following otherwise uncomplicated vitrectomy and posterior cortical vitreous peeling for stage 2 and 3 FTMHs and discuss the possible underlying mechanisms.

\section{Patients and methods}

We studied retrospectively five patients who reported the onset of a peripheral field defect following macular hole surgery. Four were female and one male, aged 50-73 (mean 63) years. Two had mild hypertension controlled with one medication. One patient (case 4) had non-insulin dependent diabetes mellitus and had been treated successfully with a macular laser grid 5 years previously in the same eye. At the time of the macular hole surgery, no significant diabetic macular oedema was present. One patient (case 2) had red-green colour deficiency.

One eye was operated on for a stage 2 and four eyes for stage 3 FTMH, with preoperative visual acuities of 6/60-6/24 (mean 6/36). All five eyes had similar procedures for stage 2 and 3 FTMHs, without apparent complications. Briefly, following a three port pars plana vitrectomy, adherent posterior cortical vitreous was engaged, in the region of the optic disc or over the peripapillary retina, using the vitreous cutter with active aspiration. The layer was then stripped anteriorly beyond the equator, and the vitrectomy completed. Epiretinal membrane dissection was performed where necessary and the peripheral retina and entry sites carefully examined for iatrogenic breaks. This was followed by fluid-air exchange and aspiration of subretinal fluid from the cuff around the FTMH, with a 34 gauge microcannula, and drying under air for 10 minutes. Where autologous serum was used, $0.1-0.2 \mathrm{ml}$ were applied procedure was completed with an air-gas exchange. As postoperative tamponade is believed to increase surgical success, ${ }^{5-8}$ we prefer perfluoropropane $\left(\mathrm{C}_{3} \mathrm{~F}_{8}\right)$ 14-16\% which provides a longer lasting gas bubble, allowing tamponade for at least 14-21 days.

Postoperatively, patients were instructed to posture in the face down position for at least 2 weeks, and were examined on the first day, at 2 
weeks, 6 weeks, and at 3 monthly intervals thereafter. Chloramphenicol eyedrops $0.5 \%$ four times daily, dexamethasone $0.1 \%$ four times daily, and atropine $1 \%$ twice daily were used for all operated eyes.

All five patients reported a peripheral field defect after the gas bubble had completely resolved. A full ocular and neuro-ophthalmic assessment was performed between 8 and 16 weeks after surgery, and all field defects were confirmed with Humphrey and Goldmann perimetry. As this was an unexpected finding, preoperative fields were not available for comparison. In all eyes, we attempted to determine the postoperative configuration of the hole, identify any retinal or retinal vascular pathology, assess retinal nerve fibre layer (RNFL) integrity and optic disc characteristics, and to record macular, peripheral retinal, and optic nerve function.

Clinical examination included a full slitlamp and funduscopic examination followed by neuro-ophthalmic assessment. Best corrected visual acuity, Ishihara colour scores, pupillary reflexes (graded as trace, mild, moderate, severe), automated Humphrey perimetry (30-2 and 60-2), and Goldmann kinetic perimetry were determined. Full fundal examination was performed with direct and indirect ophthalmoscopy, $78 \mathrm{D}$ fundal lens, three mirror Goldmann contact lens, and macular contact lens with full mydriasis. Optic disc drusen were excluded in all patients by ultrasound and blue pre-fluorescein photography. All patients had fundal photography, including red-free images, and fundal fluorescein angiography between 8 and 16 weeks postoperatively, after which photography was repeated at 3 month intervals. Electrodiagnostic testing was performed between 12 and 24 weeks postoperatively in all patients.

\section{ELECTRODIAGNOSTIC AND PSYCHOPHYSICAL}

EVALUATION

We performed focal electroretinography (ERG) to evaluate outer retinal function in the scotomatous area, compared with the unaffected quadrants in the same eye and corresponding quadrants in the fellow eye. Cortical visual evoked potentials (VEP) were also obtained.

\section{Focal ERG}

We used an ERG and visual stimulator which consists of a $5 \mathrm{~cm}$ bowl, concave side pointing to the patient's eye, which is back illuminated by a number of light emitting diodes (LEDs). The light from the diodes is diffused, and when the bowl is placed as near as possible to the eye, it forms a ganzfeld. The diodes are contained in a $5 \mathrm{~cm}$ plastic tube mounted on a pantographic arm, and could thus easily be directed to the eye from any point in visual space. In this investigation, the bowl was withdrawn to $28 \mathrm{~cm}$ from the cornea, so as to illuminate a $10^{\circ}$ segment of the visual field. The tube containing the bowl was mounted onto a large sheet of white plastic on which fixation spots were placed appropriately. The fixation spots and the plastic surround were illumi- nated with red light to minimise stray light. By moving the fixation spot in front of the patient, and angling the stimulator appropriately, the desired regions of retina could be illuminated.

Focal ERG responses were recorded from the fovea and from the scotomatous area. The latter were then compared with focal ERGs from unaffected quadrants in the affected eye and from quadrants in the fellow eye.

Focal foveal responses were recorded with the subject fixating on the centre of the stimulus, using an inbuilt luminous fixation point built into the bowl. Individual quadrants were stimulated by the subject fixating on a point $19.4 \mathrm{~cm}$ from the centre of the bowl, so as to stimulate a segment of visual field $31^{\circ}$ to $38^{\circ}$ from fixation (that is, within the scotoma in affected quadrants). For example, to stimulate the inferotemporal quadrant of the right field - that is, the superonasal retina - the subject fixates on a point $19.4 \mathrm{~cm}$ superonasally to the centre of the stimulus.

In order to demonstrate that the responses were indeed focal, rather than attributable to stimulation of other areas by scattered light, we used an orange stimulus of $3 \mathrm{~ms}, 460 \mathrm{Td}-\mathrm{s}$ $610 \mathrm{~nm}$ superimposed on a $32 \mathrm{Td}-\mathrm{s} 665 \mathrm{~nm}$ background. This produces large cone responses foveally, but very small responses in the retinal periphery to be tested, where the density of cones is much less, thus proving that scatter from the periphery to the fovea was negligible. For the focal ERG studies described here, a combination of orange ( $3 \mathrm{~ms} 460 \mathrm{Td}-\mathrm{s}$ $610 \mathrm{~nm}$ ) and blue ( $3 \mathrm{~ms} 57 \mathrm{Td}-\mathrm{s} 460 \mathrm{~nm}$ ) light on a $32 \mathrm{Td} 665 \mathrm{~nm}$ background was used so that the predominantly rod driven ERGs from the retinal periphery and the cone driven ERGs at the fovea could be elicited by the same stimulus.

Since the ERG amplitude has a considerable intersubject variation, focal peripheral ERGs were also expressed as a fraction of the amplitude of the foveal response, decreasing the dispersion of results.

\section{Visual evoked cortical responses (VER)}

The cortical evoked response to the same flashes was recorded. The large n1-pl complex recorded after foveal stimulation was absent when the periphery was stimulated in all quadrants of affected and normal fellow eyes. Thus the stimulus conditions made it possible to record focal VER responses only when the fovea was stimulated. Standard full VER responses were also recorded in affected and fellow eyes.

\section{Colour contrast sensitivity (CCS)}

Colour contrast thresholds were measured with the computer graphics system described by Arden et al, ${ }^{10}$ which has been used for contrast threshold testing in glaucoma, ${ }^{11}$ using a modification of the 'ring' technique described by Tak Yu and Arden. ${ }^{12}$ The original program has been modified so that the thresholds in each of 4 quadrants can be estimated simultaneously. The patients were placed $22 \mathrm{~cm}$ from the screen, so that the colour contrast thresholds were determined $30-35^{\circ}$ from fixation- 


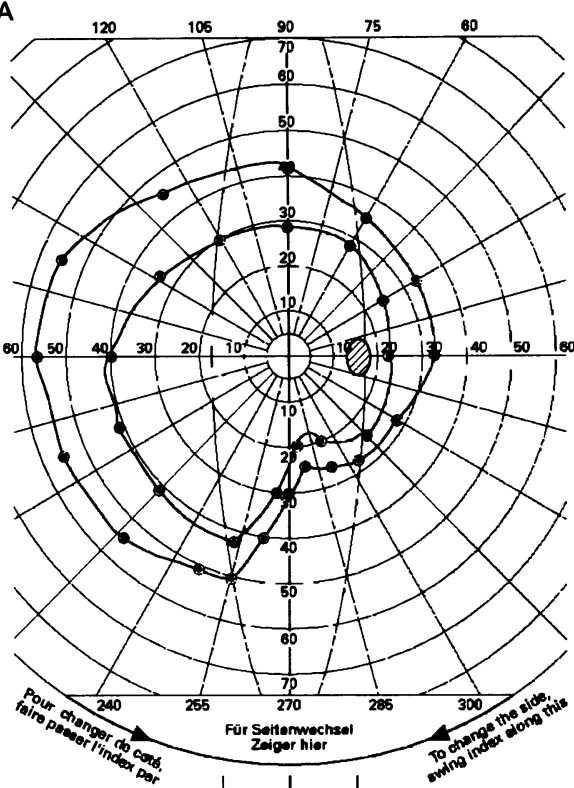

C

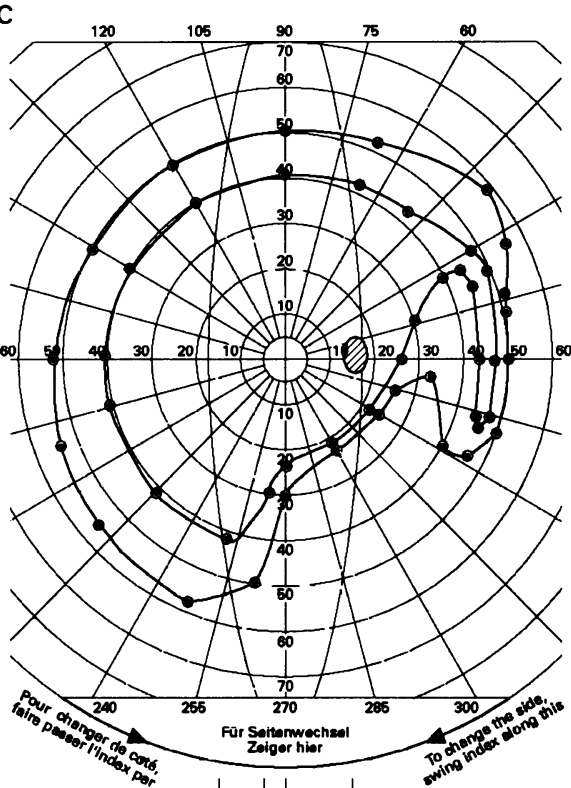

E

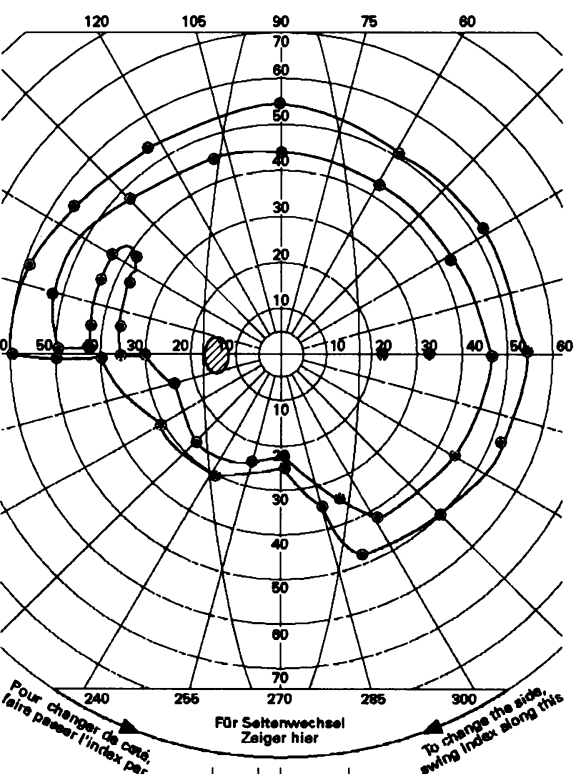

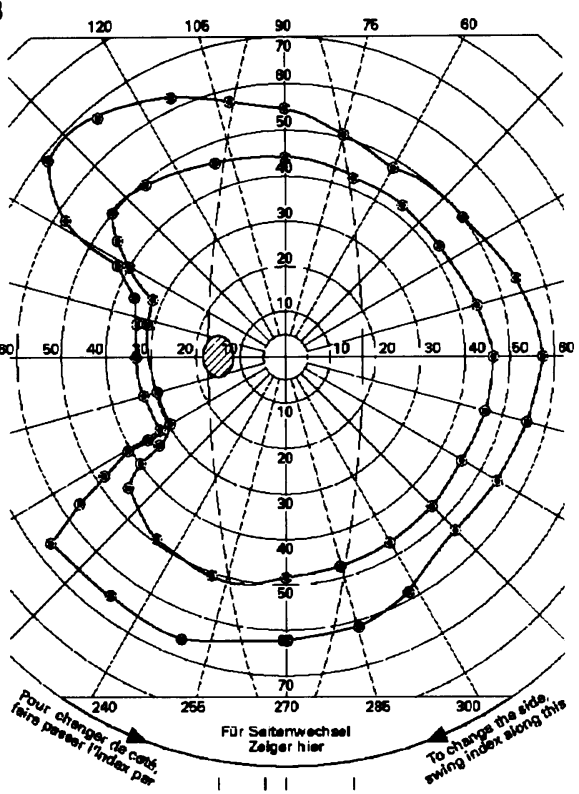
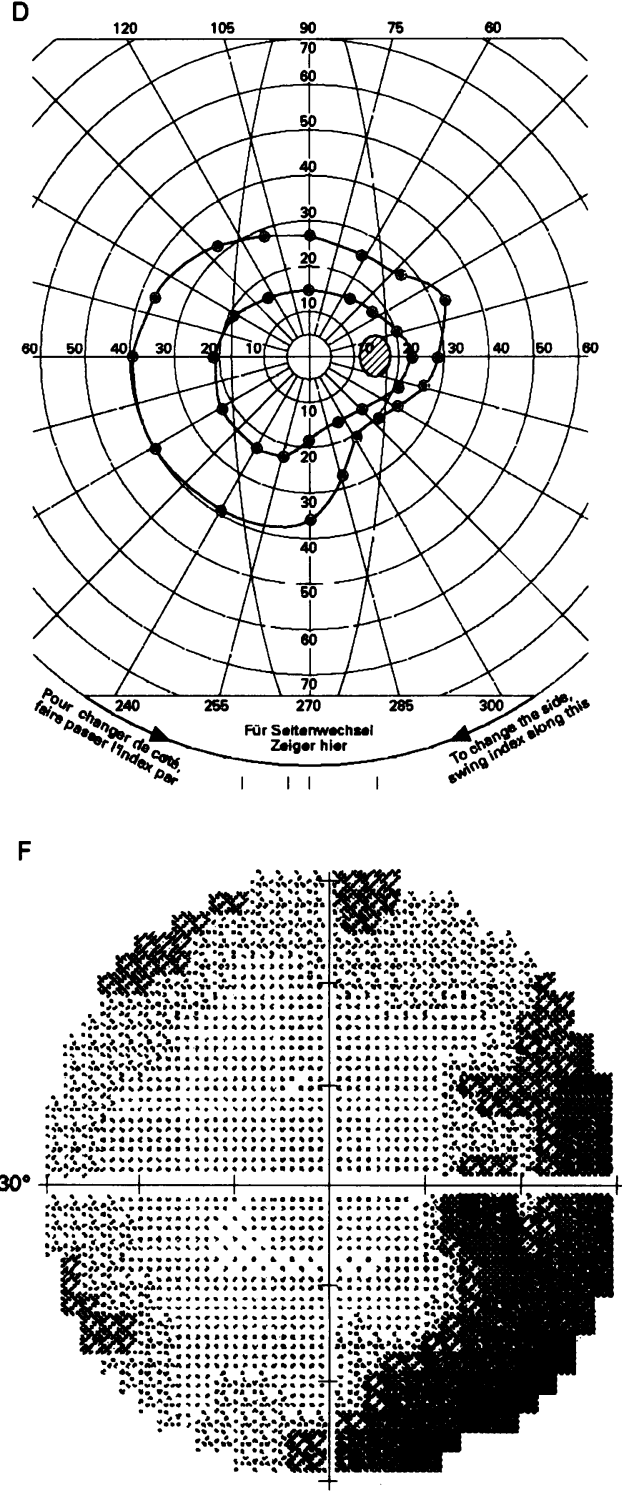

Figure 1 Postoperative Goldmann perimetry, with III4e and I4e targets, shows inferotemporal or temporal scotomas in all eyes $(A-E)$. Humphrey automated perimetry (30-2) in case 1 shows a similar defect (F). Case 4 (D) had more widespread constriction and case 5 (E) had a partial altitudinal component. 
Table 1 Summary of clinical cases

\begin{tabular}{|c|c|c|c|c|c|}
\hline & \multicolumn{5}{|l|}{ Case number } \\
\hline & 1 & 2 & 3 & 4 & 5 \\
\hline Age / sex & $50 / \mathrm{F}$ & $69 / M$ & $61 / \mathrm{F}$ & $62 / F$ & $73 / \mathrm{M}$ \\
\hline Medical history & Nil & Mild hypertension & Nil & NIDDM & Mild hypertension \\
\hline Side & Right & Left & Right & Right & Left \\
\hline Refraction & Plano & Plano & +1.00 left eye & Plano & -3.00 left eye \\
\hline Hole stage & 2 & 3 & 3 & 3 & 3 \\
\hline Preop VA & $6 / 36$ & $6 / 24$ & $6 / 24$ & $6 / 60$ & $6 / 60$ \\
\hline Postop hole & Open & Closed & Open & Closed & Closed \\
\hline Postop VA & $6 / 60$ & $6 / 12$ & $6 / 18$ & $6 / 9$ & $6 / 12$ \\
\hline Field loss & Inferotemporal & Temporal wedge & Inferotemporal & $\begin{array}{l}\text { Inferotemporal } \\
\text { General } \\
\text { constriction }\end{array}$ & $\begin{array}{l}\text { Inferotemporal } \\
\text { Partial altitudinal }\end{array}$ \\
\hline Ishihara score & $12 / 13$ & $\begin{array}{l}\text { Red/green colour } \\
\text { defect }\end{array}$ & $13 / 13$ & $5 / 13$ & $5 / 13$ \\
\hline RAPD & Mild & - & Mild & - & Mild \\
\hline Disc pallor & Nasal & - & Nasal & - & Nasal \\
\hline Disc anatomy & Small, crowded & Normal & Normal & Normal & Normal \\
\hline RNFL & Nasal defect & Normal & Nasal defect & Normal & Nasal defect \\
\hline Other fundal signs & - & - & - & $\begin{array}{l}\text { Background DR, } \\
\text { treated } \\
\text { maculopathy }\end{array}$ & $\begin{array}{l}\text { Mild hypertensive } \\
\text { vascular changes }\end{array}$ \\
\hline Follow up & 12 months & 6 months & 7 months & 8 months & 6 months \\
\hline
\end{tabular}

VA = visual acuity; RAPD = relative afferent pupillary defect; $R$ NFL = retinal nerve fibre layer; NIDDM = non-insulin dependen diabetes; $\mathrm{DR}=$ diabetic retinopathy.

that is, in the regions where the ERGs were recorded. Colour vision was tested along standard protan colour confusion axes. In these patients we assumed that the colours were isoluminant, and did not make individual corrections as was done in the original description of the tests.

\section{Results}

The patient data are summarised in Table 1 . All five patients had uneventful macular hole surgery and neither papillary nor peripapillary haemorrhages were noted intraoperatively in any of the eyes. No hypotensive episodes were recorded during general anaesthesia in any of the patients.

In the early postoperative period, intraocular pressure (IOP) remained normal throughout, except in case 2, where an IOP of $35 \mathrm{~mm} \mathrm{Hg}$ was noted on the first postoperative day, returning to normal after a single oral dose of acetazolamide $500 \mathrm{mg}$. The hole was closed in three eyes and remained open in two eyes. Although good gas fills were present in all eyes during the first 2 to 3 postoperative weeks, partially obscuring fundal examination, a sufficiently detailed view was present in all eyes and no signs suggestive of optic disc or retinal vascular pathology were evident during this period.

Table 2 Focal electroretinography (ERG) responses

\begin{tabular}{|c|c|c|c|c|c|c|}
\hline \multirow[b]{2}{*}{ Case } & \multicolumn{4}{|c|}{ Focal ERG (amplitude in $\mu V$ ) } & \multicolumn{2}{|l|}{ Ratios } \\
\hline & $\begin{array}{l}\text { Inferotemporal } \\
\text { (scotoma) }\end{array}$ & Inferonasal & Superonasal & Foveal & $\begin{array}{l}\text { Inferotemporall } \\
\text { fovea }\end{array}$ & Other/fovea \\
\hline 1 & 9.77 & 8.63 & 9.29 & 8.64 & 1.13 & 1.00 \\
\hline 2 & 6.15 & 5.85 & 3.81 & 4.04 & 1.52 & 1.45 \\
\hline 3 & 8.35 & 9.61 & 13.00 & 14.50 & 0.58 & 0.66 \\
\hline 4 & 4.00 & 3.36 & $-\star$ & 4.13 & 0.97 & 0.81 \\
\hline 5 & 8.64 & 6.25 & 9.28 & 9.52 & 0.91 & 0.66 \\
\hline Mean & 7.38 & 6.74 & 8.85 & 8.17 & 1.02 & 0.92 \\
\hline SD & 2.30 & 2.46 & 3.79 & 4.34 & 0.35 & 0.33 \\
\hline SE & 1.03 & 1.10 & 1.69 & 1.94 & 0.15 & 0.15 \\
\hline
\end{tabular}

^ Quadrant not tested.

The values are also expressed as ratios of the foveal response and the two right hand columns compare the scotomatous quadrant and the unaffected quadrants (mean) of the same eye.
VISUAL FUNCTION AND PERIPHERAL FIELDS

All patients noted an absolute inferotemporal scotoma between 4 and 8 weeks postoperatively, as the gas diminished. In the eyes with closed holes, best corrected visual acuities of $6 / 9-6 / 12$ were recorded and in those with open holes, acuities of $6 / 60$ and $6 / 18$. Ishihara scores varied from $5 / 13$ to $12 / 13$ and colour desaturation varied from mild to moderate and did not relate to whether the hole had been closed. Three eyes exhibited a mild relative afferent pupillary defect.

Similar, absolute field defects were recorded in all five cases, with the inferotemporal quadrant universally affected (Fig 1), encroaching to within $20-30^{\circ}$ of fixation and to within $5-15^{\circ}$ of the blind spot, which remained normal. Goldmann perimetry provided accurate mapping of scotomata, particularly in the area of the blind spot. In case 5, a partial altitudinal component was present, and in another eye (case 4), more widespread constriction was evident. All defects remained stable throughout the follow up (6-12 (mean 7.8 months)) during which time at least three field examinations were performed. Nuclear lens opacification was noted in cases 2 (mild) and 4 (moderate).

OPTIC DISC AND RETINAL NERVE FIBRE LAYER FINDINGS

Four eyes had anatomically normal discs with cup to disc ratios of between 0.2 and 0.5 . One eye had a small crowded disc without a physiological cup (case 1). Of the five eyes, three developed subtle nasal disc pallor and RNFL loss, anatomically consistent with the pattern of field loss.

\section{OTHER FUNDUS FINDINGS}

In case 4 , background diabetic retinopathy remained unchanged postoperatively, without evidence of fresh maculopathy. In case 5, mild hypertensive vascular changes had been noted before surgery and remained unchanged post- 
Combined orange ( $3 \mathrm{~ms} 460 \mathrm{Td}-\mathrm{s} 610 \mathrm{~nm}$ ) and blue ( $3 \mathrm{~ms} 57 \mathrm{Td}-\mathrm{s} 460 \mathrm{~nm}$ ) stimulus on $32 \mathrm{Td} 630 \mathrm{~nm}$ background

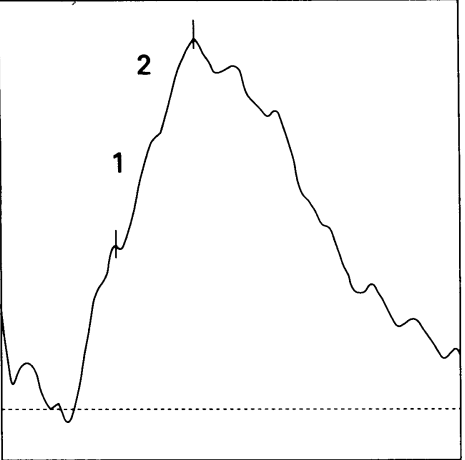

Foveal

(stimulus $10^{\circ}$ circle on fovea)

1: cone $b=50.0 \mathrm{~ms}, 7.129 \mu \mathrm{V}$

2: $\operatorname{rod} b=84.4,16 \cdot 162 \mu \mathrm{V}$

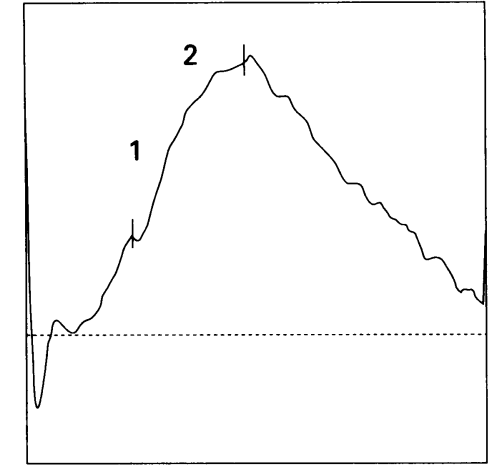

Supernasal field=inferotemporal retina (stimulus $10^{\circ}$ circle centred $34.5^{\circ}$ from fixation, at $135^{\circ}$ )

1: cone $b=46.0 \mathrm{~ms}, 4.297 \mu \mathrm{V}$

2: $\operatorname{rod} b=94 \cdot 8,11.865 \mu \mathrm{V}$
Orange ( $3 \mathrm{~ms} 460 \mathrm{Td}-\mathrm{s} 610 \mathrm{~nm}$ ) stimulus on $32 \mathrm{Td} 665 \mathrm{~nm}$ background

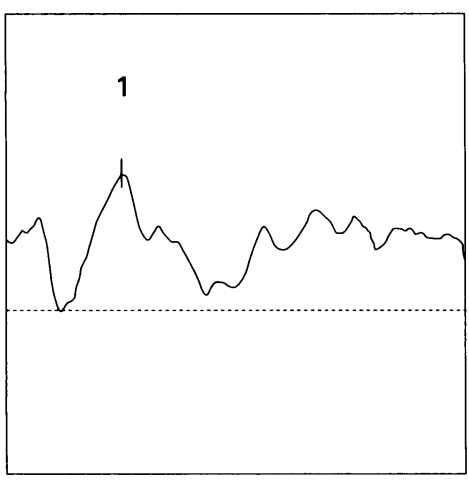

Foveal

(stimulus $10^{\circ}$ circle on fovea)

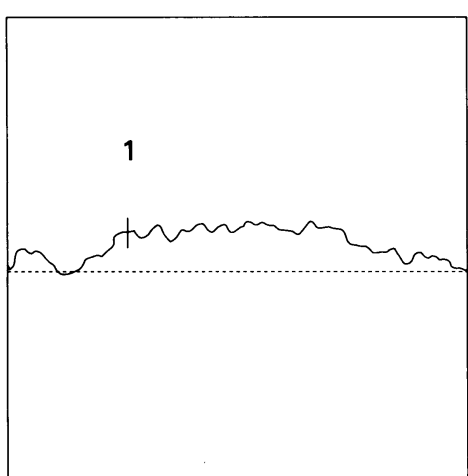

Supernasal field=inferotemporal retina (stimulus $10^{\circ}$ circle centred $31.5^{\circ}$ from fixation, at $135^{\circ}$ )

1: cone $a-b=52.4 \mathrm{~ms}, 1.66 \mu \mathrm{V}$
1: cone $a-b=50.8 \mathrm{~ms}, 5.859 \mu \mathrm{V}$ Figure 2(A) Demonstration of the focal ERG response (case 3). A combination of orange
and blue light (top) produces both a foveal and peripheral response. Orange light alone and blue light (top) produces both a foveal and peripheral response. Orange light alone the unaffected quadrant, as the rod response to this wavelength is poor. This phenomenon also demonstrates that contamination of the focal ERG, due to light scatter, is not significant.
CCS testing was carried out in three of five affected eyes (one case had a congenital colour vision defect and one had diabetes, which is known to affect colour vision). In these eyes, colour contrast was abolished in the scotomatous areas. Colour contrast was, however, recordable at the edges of scotomatous areas and revealed elevated contrast threshold, particularly for protan, compared with points on the same isoptre in unaffected quadrants and in fellow eyes.

\section{Discussion}

We have described five patients who developed peripheral field loss following routine macular hole surgery, a phenomenon which has been previously described in only one eye following surgery for a stage 3 FTMH. ${ }^{13}$ All eyes developed an absolute peripheral scotoma, affecting the inferotemporal quadrant, not contiguous with the blind spot, which remained stable. The consistent pattern of field loss implies a common aetiology and site.

The observations presented in this study confirm that field defects were caused by retinal nerve fibre loss rather than outer retinal damage. The preservation of the focal ERG in the affected quadrant, with an absent colour contrast threshold to protan, rules out outer retinal pathology. Photoreceptor toxicity, due to intraocular gas or autologous serum, and outer retinal or choroidal ischaemia are therefore unlikely to play a role. Retinal vascular occlusion would also appear unlikely in view of the lack of clinical signs postoperatively, and the lack of ERG b-wave abnormality. ${ }^{14}{ }^{15}$ Preservation of focal foveal VER and full VER responses, which are dominated by the papillomacular region suggests that the RNFL was largely intact in this area. The possibility of a mechanical effect, from the gas bubble, on the RNFL also appears rather remote, as similar defects have been described after vitrectomy and posterior cortical peeling for excision of subfoveal choroidal neovascular membranes, ${ }^{13}$ where gas tamponade was not used.

The precise location of nerve fibre damage cannot be determined on the basis of the electrophysiological tests available for this study, in that the VEE measures overall retinocortical function, while the ERG reflects outer retinal function. Although the pattern ERG (PERG) may be used to assess inner retinal function, responses can only be analysed if the stimulus is focused on the fovea and it is therefore of limited use in detecting focal inner retinal abnormalities.

However, considerable circumstantial evidence indicates that the site of nerve fibre damage is at the optic disc or peripapillary RNFL rather than at the peripheral RNFL, and is probably due to traction during cortical vitreous peeling. Firstly, field defects have not, thus far, been described in eyes undergoing surgery for stage 4 holes, where the vitreous cortex is already detached. Secondly, intraoperative observations during this manoeuvre suggest that vitreopapillary traction occurs in most cases, and that the firmest vitreous adhesions occur at the optic disc and peripapillary affected scotomatous quadrants/fovea and from unaffected quadrants/fovea were comparable in all eyes. Furthermore, focal ERGs from affected quadrants were comparable with quadrantic responses from fellow control eyes. 
B

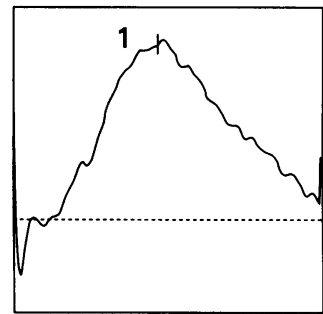

Superonasal field= inferotemporal retina 1: $b=94 \mathrm{~ms}, 11.377 \mu \mathrm{V}$

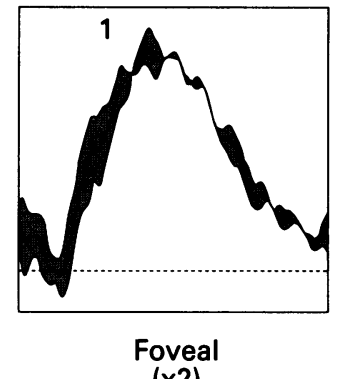

(x2)

1: $b=82 \mathrm{~ms}, 14.502 \mu \mathrm{V}$

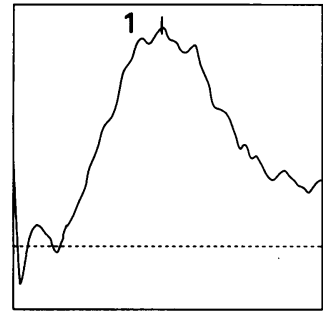

Inferonasal field= superotemporal retina 1: $b=92.8 \mathrm{~ms}, 9.61 \mu \mathrm{V}$

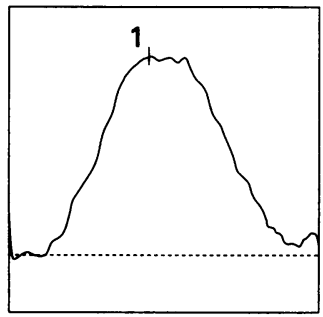

Superotemporal field $=$ inferonasal retina

$1: b=91.6 \mathrm{~ms}, 12.988 \mu \mathrm{V}$

All five eyes in our study demonstrated temporal field loss which may reflect the fact that vitreopapillary adhesions are firmer at the nasal aspect of the disc and that greater forces are required to separate them. This would certainly be in keeping with intraoperative observations, where the nasal aspect is the last to separate and is the most frequent site of superficial haemorrhage (Gregor, Ezra, and Aylward, unpublished data). Observations during spontaneous PVD have also confirmed that nasal papillary adhesions are the last to separate $^{17}$ and that the nasal rim is predisposed to haemorrhages ${ }^{18-20}$ which may be associated with temporal field loss. ${ }^{18}$ The generalised field constriction in case 4, in view of the absence of an afferent pupillary defect suggests that it may have been secondary to nucleosclerosis rather than diffuse nerve fibre loss.

Finally, anatomical studies have shown that axons in the RNFL, originating from more peripheral ganglion cells, pass to the peripheral optic nerve and the axons from more central ganglion cells enter at the central portion of the nerve head. ${ }^{21}{ }^{22}$ The preservation of the blind spot in all eyes in this study suggests that the optic disc rim rather than the central portion is affected and would correlate with the observations already cited. The partial altitudinal component in case 5 also indicates that fibre loss may have occurred predominantly at the nasal rim, possibly due to microvascular disruption in this area.

Although papillary and peripapillary traction clearly occurs during cortical vitreous peeling, its mechanical effects remain unclear. Whether nerve fibre loss occurs as a result of shearing forces or microvascular damage, or both, is a matter for speculation. Furthermore, the presence of cardiovascular risk factors in three patients may indicate a predisposition to nerve fibre loss in cases with an already compromised papillary and peripapillary circulation, where insults to the nerve fibre layer are less well tolerated. The visual field loss documented in these patients has implications for any vitreoretinal procedure involving posterior vitreous cortex stripping. Careful surgical technique, using the minimum amount of force to effect vitreous separation, is clearly important. Passive aspiration may reduce tractional forces but may not provide sufficient force to complete the manoeuvre in all cases. The true incidence of this complication following macular hole surgery remains unclear, as subclinical field defects may occur and remain undetected in some patients. In this respect, prospective studies comparing preoperative and postoperative fields, in all subjects undergoing surgery for stage 2 and 3 holes, appear warranted.

Histopathological studies have also shown that the most adherent areas of posterior cortical vitreous are at the optic disc. ${ }^{16}$ Clinical observations on the progression of uncomplicated spontaneous posterior vitreous detachment (PVD) have confirmed this to be the last area to separate. ${ }^{17}$ In addition, vitreopapillary traction has been observed in eyes which develop optic disc haemorrhages ${ }^{18-20}$ and peripheral field loss in association with spontaneous PVD. ${ }^{18}$ other retinal pathology. $1 / 2$

The work was supported by the Guide Dogs for the Blind Association and the Moorfields Special Trustees (Stringer Bequest). The authors would also like to thank Mr Michael Sanders for his contribution to the discussion.

1 Gass JDM. Idiopathic senile macular hole: its early stages and development. Arch Ophthalmol 1988;106:629-39.

2 Gass JDM. Reappraisal of biomicroscopic classification of stages of development of a macular hole. Am $\mathcal{Y} O$ phthalmol 1995;119:752-9.

3 Kelly NE, Wendel RT. Vitreous surgery for idiopathic macular holes: results of a pilot study. Arch Ophthalmol 1991;190:654-9. 
4 Wendel RT, Patel AC, Kelly NE, Salzano TC, Wells JW, Novack GD. Vitreous surgery for macular holes. Ophthalmology 1993;100:1671-6.

5 Glaser BM, Michels RG, Kupperman BD, Sjaarda RN Pena RA, et al. The effects of pars plana vitrectomy and transforming growth factor-beta 2 for the treatment of fullthickness macular holes: a prospective randomised study. thickness macular holes: a prospect

6 Lansing MB, Glaser BM, Liss H, Hanham A, Thompson

Lansing MB, Glaser BM, Liss H, Hanham A, Thompson
JT, Sjaarda RN, et al. The effect of pars plana vitrectomy $\mathrm{JT}$, Sjaarda RN, et al. The effect of pars plana vitrectomy
and transforming growth factor-beta 2 without epiretinal and transforming growth factor-beta 2 without epiretinal thalmology 1993;100:868-71.

7 Orrellana J, Lieberman RM. Stage III macular hole surgery. Br f Ophthalmol 1993;77:555-8.

8 Smiddy WE, Glaser BM, Thompson JT, Sjaarda RN, Flynn HW, Hanham A, et al. Transforming growth factor-beta 2 sionificantly enhances the ability to flatten the rim of subretinal fluid surro subretinal fluid sureunding macular holes: preliminary anatomic results of a multicentre study. Retina 1993;13:296-301.

9 Ryan EH, Gilbert HD. Results of surgical treatment of recent onset full-thickness idiopathic macular holes. Arch Ophthalmol 1994;112:1545-53.

10 Arden GB, Gunduz K, Perry S. Colour vision testing with a computer graphics system. Clin Vis Sci 1988;2:303-20.

11 Devos M, Arden GB. Peripheral colour contrast sensitivity in glaucoma and ocular hypertension. Eye 1996 (in press).

12 Yu TC, Falcao-Reis F, Spileers W, Arden GB. Peripheral colour contrast. A new screening test for preglaucomatous visual loss. Invest OphthalmolVis Sci 1991;32:2779-89.
13 Melberg NS, Thomas MA. Field loss after pars plana vitrectomy with air/fluid exchange. Am $\mathcal{F}$ Ophthalmol 1995;120: 386-8.

14 Johnson MA, Finkelstein D, Massof RW. Retinal function in branch vein occlusion. Invest Ophthalmol Vis Sci 1983;24: 296.

15 Kaye SB, Harding SP. Early electroretinography in unilateral central retinal vein occlusion as a predicator of rubeoeral central retinal vein occlusion as a predicat

16 Foos RY. Posterior vitreous detachment. Trans Am Acad Ophthalmol Otolaryngol 1972;76:480-97.

17 Busacca A. Biomicroscopie et Histopathologie de L'Oeil. Vol III: Corps Vitre-Biomicroscopie Du Fond de L'Oeil. Zurich: Schweizer Druck-und Verlagshaus, 1967.

18 Katz B, Hoyt WF. Intrapapillary and peripapillary haemorrhage in young patients with incomplete posterior vitreous detachment: signs of vitreopapillary traction. Ophthalmology 1995;102:349-54.

19 Bruillette G. Haemorrhagie papillaire associee au decollement du vitre posterieur. Can $\mathcal{f}$ Ophthalmol 1978;13:81-5.

20 Roberts TV, Gregory-Roberts JC. Optic disc haemorrhages in posterior vitreous detachment. Aust $N Z \mathcal{F}$ Ophthalmol 1991;19:61-3.

21 Walsh FB, Hoyt WF. In: Miller NR. Clinical neuroophthalmology. 4th ed. Vol I. Baltimore: Williams \& Wilkins, 1982: 26-43.

22 Minckler DS. The organisation of nerve fiber bundles in the primate optic nerve head. Arch Ophthalmol 1980;98: primate 